\title{
Editorial
}

\section{ANDREAS - AN IDOL FOR MANY YOUNG ANATOMISTS AND CLINICIANS}

\author{
Georg Feigl ${ }^{1}$, Susana N. Biasutto ${ }^{2}$ \\ ${ }^{1}$ Department of Anatomy, Medical University of Graz, Graz, Austria \\ ${ }^{2}$ Chair of Normal Anatomy, Faculty of Medical Sciences, National University of Cordoba, \\ Cordoba, Argentina
}

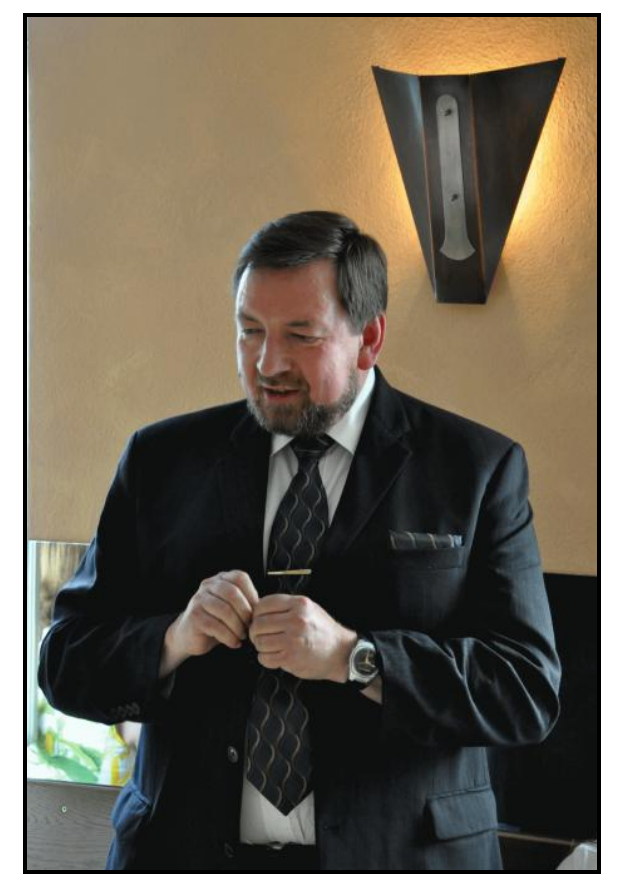

On the $7^{\text {th }}$ February, AoUniv. Prof. Dr. med. univ. Andreas Weiglein surprisingly and sadly passed away. To the very end, he was working at the Department of Macroscopic and Clinical Anatomy of the Medical University of Graz. Without sparing himself, he continued to work at the department without regard of his health and supervised the education of dental medical students at the Medical University of Graz.

But who was this extraordinary and impressive person?

Andreas Weiglein studied Medicine at the KarlFranzens University of Graz. As the studying in Graz was characterized by Anatomy very much, he decided to specialize on Anatomy. Supported by his teachers Univ. Prof. Walter Thiel and Univ. Prof Friedrich Anderhuber he had the luck to have two very strong mentors in the field of Macroscopic and Clinical Anatomy. From the very beginning he became an enthusiastic competent teacher and researcher. What is more, he searched for international contacts and opened the "Graz view". He participated in conferences of the European Association of Clinical Anatomy but also meetings of the Argentine Association of Clinical Anatomy, the American Association of Clinical Antomists and the American Association of Anatomists. His level and competence was shown by "Best presentation awards" at such meetings. As a consequence he became reviewer and Associated Editor of several anatomical journals.

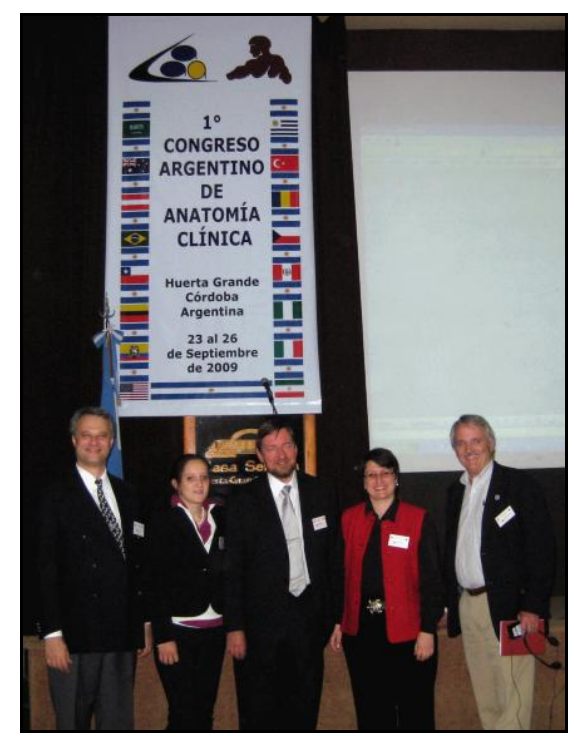

$2009-1^{\text {st }}$ First Argentine Congress of Clinical Anatomy. From left to right: Cristian Stefan, Angelika Schwarz, Andreas Weiglein, Anca Stefan and Stephen Carmichael. Cordoba. 


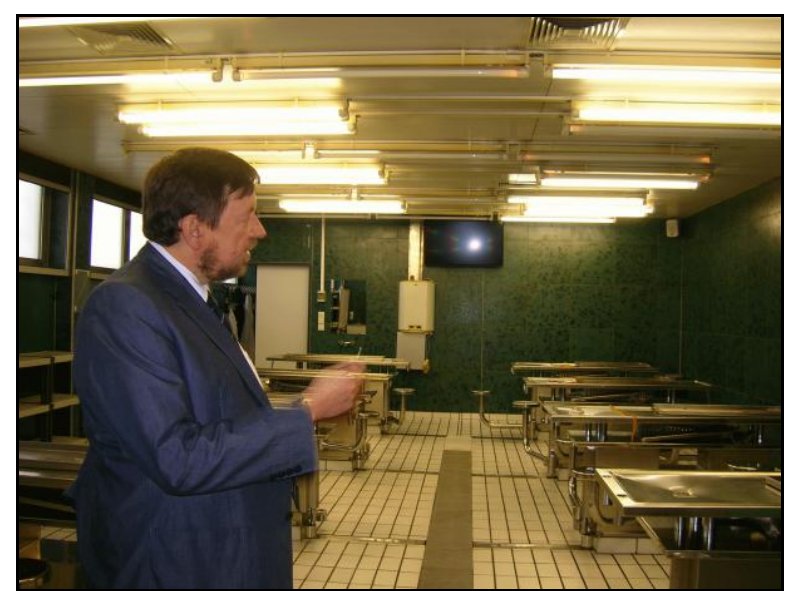

2013 - Prof. Weiglein in the Department of Anatomy, Medical University of Graz, Austria.

He never stayed a member only but wanted an association to progress and to increase the standard of the associations as well as journals where was always welcomed by the Editors of these journals.

This can be seen by the International Society for Plastination. He was one of the Key-Members and became president of the Society and experimented with plastination a lot. Recognizing the advantage of this preservation method plastination was implemented in Graz for teaching purposes.

Anyway, Andreas was an enthusiastic openminded person bringing together the colleagues from all over the world. His sense of networking can be seen by the unforgettable meetings of which he was organizer or co-organizer. The Joint meeting of the EACA and AACA in 2003 as well as the Meeting of the Anatomische Gesellschaft (1998) and the International Plastination Society meeting in 1994 are proof of his vision to unify the specialists and encourage them to network and to progress.

$\mathrm{He}$ also encouraged young anatomists to visit Graz and supported new journals by submitting manuscripts to these journals knowing that they might not receive an impact factor for a long time. Andreas Weiglein was an idol for many young anatomists in the world; he will be kept in our memory and in our heart as a person who wanted to support everybody in the world.

Dear Andreas, requiescat in pace!

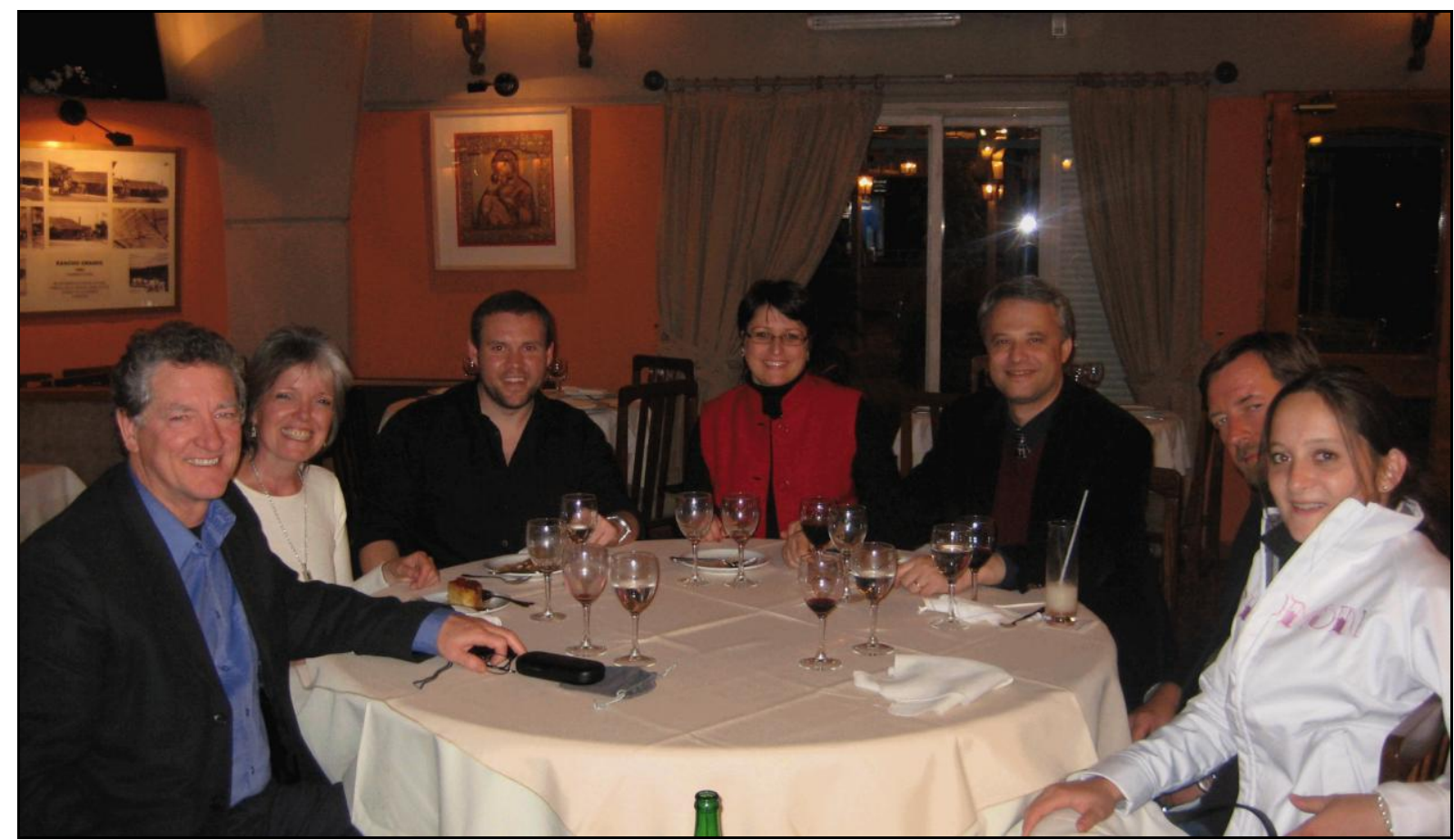

Geoff Meyer, Susana Biasutto, Adrian Castagno, Anca Stefan, Cristian Stefan, Andreas Weiglein, Angelika Schwarz. Dinner in Cordoba - Argentina. 